\title{
HYPERSPECTRAL HYPERION IMAGERY ANALYSIS AND ITS APPLICATION USING SPECTRAL ANALYSIS
}

\author{
W. Pervez ${ }^{\text {a }}$, S. A. Khan ${ }^{\text {b }}$, Valiuddin ${ }^{\text {c }}$ \\ ${ }^{a}$ National University of Sciences and Technology Islamabad, Pakistan - wasim_pervaiz@pnec.nust.edu.pk \\ ${ }^{\mathrm{b}}$ National University of Sciences and Technology Islamabad, Pakistan - shoabak@ @eme.edu.pk \\ ${ }^{\mathrm{c}}$ Hamdard University Karachi, Pakistan- v_uddin@ hotmail.com
}

KEY WORDS: Hyperion, hyperspectral, land cover mapping, Imagery Pre-processing, Principle Component Analysis, vegetation delineation

\begin{abstract}
:
Rapid advancement in remote sensing open new avenues to explore the hyperspectral Hyperion imagery pre-processing techniques, analysis and application for land use mapping. The hyperspectral data consists of 242 bands out of which 196 calibrated/useful bands are available for hyperspectral applications. Atmospheric correction applied to the hyperspectral calibrated bands make the data more useful for its further processing/ application. Principal component (PC) analysis applied to the hyperspectral calibrated bands reduced the dimensionality of the data and it is found that $99 \%$ of the data is held in first 10 PCs. Feature extraction is one of the important application by using vegetation delineation and normalized difference vegetation index. The machine learning classifiers uses the technique to identify the pixels having significant difference in the spectral signature which is very useful for classification of an image. Supervised machine learning classifier technique has been used for classification of hyperspectral image which resulted in overall efficiency of 86.6703 and Kappa co-efficient of 0.7998 .
\end{abstract}

\section{INTRODUCTION}

Hyperion instrument can capture 256 spectra each with 242 spectral bands. (Barry, 2001; Beck, 2003 \& Pengra, Bruce W, Johnston, Carol A, Loveland, Thomas R , 2007) . Hyperion covers the area perpendicular to the motion of the satellite (Kruse, F. A ,1996; Kruse, F. A., 2003; Kruse, FA, Boardman, 2002). Land cover thematic mapping can be determined using remote sensing data to provide important information for performing temporal land cover change analysis (Kavzoglu, 2009).Thus for thematic information extraction several previous studies employed multispectral imagery for land use/cover mapping application (Canty, in press ; Dixon, 2008; Huang, 2002; Nemmour,2006). In hyperspectral image, imaging system such as Thematic Mapper, Landsat Multi Spectral System or SPOT can be used for land surface cover features (Hong SY, 2002; Huete AR, 2003). Supervised classification can be used for classification and is defined as the process of using samples of known classes to classify the remaining unknown pixels to these classes with in the image (Campbell, J. B. 1996). In supervised classification, estimates are derived from the training samples which include number of classes be specified in advance (Plaza, 2005; Plaza, 2009; Small, C. 2001). Using Hyperion hyperspectral imagery, accuracy of different classification approaches for land use mapping is rare in the literature (Du, P.,2010; Pignatti, S., 2009; Walsh, S. J., 2008; Wang, J., 2010).

Since large number of bands is available in Hyperion hyperspectral image, therefore its pre-processing is different and is required before further analysis. The processed hyperspectral data can be used for different application after reducing the volume and dimensionality of the data. The processed hyperspectral data also enable traditional classification methods application on few selected bands having relevant information. In this paper pre-processing of Hyperion Hyperspectral orthoimage, application of Quick Atmospheric Correction ,
Principle Component analysis, vegetation delineation and normalized difference vegetation index, spectral profile of different classes and machine learning supervised classifier i.e spectral angle mapper will be used to achieve higher overall efficiency of classification.

\section{STUDY AREA}

The study area, is EO11500372005285110KF_1T. The Hyperion data are provided in GeoTIFF format. The Hyperion product includes a metadata file and multiple image bands. The product corner fields within the metadata files reflect the corners of the image area.

\section{DATA SETS}

The imagery is orthoimage and was acquired as a full long scene i.e 185-km tile and processing level 1(L1_T).

\section{DATA PRE-PROCESSING}

Hyperion includes digital number to radiance transformation, radiance to reflectance conversion and atmospheric corrections /reflectance retrieval.

\subsection{DN To Radiance Conversion}

EO1-Hyperion hyperspectral image consists of number of continuous spectral bands, each pixel of which stored the energy as a digital number (DN). Stacked image is used to convert DN into Radiance values. The digital numbers were stored as 16-bit signed integer. Image was converted into absolute radiance by using following equation. Each band of NIR (1 to 70) and SWIR (71 to 242) was divided by its scale factor i.e 40 and 80 respectively (Thenkabail PS, 2004a). 
$\underline{\text { VNIR }}, \underline{\text { SWIR }}$

40,80

The image is stored in ENVI Standard format and then it is converted in BIL (Bit in Line) data format.

\subsection{Radiance to Reflectance Conversion}

To convert the radiance into reflectance, following formula is used on individual band and was stacked in further processing steps (ThenkabailPS,2004b):

$$
\frac{\pi L_{\lambda} d^{2}}{\cos \theta_{s} \cdot E S U N_{\lambda}}
$$

Where

$\rho \mathrm{p}=$ Unit less planetary reflectance

$\mathrm{L} \lambda=$ Spectral radiance at the sensor's aperture

$\mathrm{d}=$ Earth-Sun distance in Astronomical units

$E S U N_{\lambda}=$ Mean solar Exo-atmospheric irradiances

$\theta \mathrm{s}=$ Solar zenith angle in degrees

Earth-sun distance was calculated using following equation $\mathrm{d}=1-0.01672 * \operatorname{Cos}(0.9856 *($ Julian Day -4$))$

\subsection{Quick Atmospheric Correction (QUAC)}

It is a scene based empirical approach used for the removal of atmospheric effects. It is based on the radiance values of the image/scene. QUAC model provides atmospheric correction of multispectral and hyperspectral imagery in VNIR to SWIR wavelength ranges. As compared to other methods, it used atmospheric compensation factors directly from the information contained within the image scene, without ancillary information. It has relatively faster computational speed as compared to other methods. QUAC provided better retrieval of reasonable reflectance spectra even if an image didn't have proper wavelength or radiometric calibration or solar illumination intensity be unknown (Agrawal, 2011). Preprocessing on the hyperspectral Hyperion orthoimage imagery was carried out by using the Hyperion tool.sav toolkit and was converted in ENVI into ENVI format files that contain information of bad band, wavelength, full width half maximum. Subsequently QUAC is applied in ENVI to provide atmospheric correction to hyperspectral imagery in VNIR to SWIR wavelength ranges. QUAC will provide better results for further processing.

\section{RESULTS AND DISCUSSION}

Hyperion orthoimage raw data analysis revealed that out of the total of 242 bands, 44 non calibrated bands have zero values which are set during level 1B pre-processing. Zero band values are bands from 1 to 7 , bands from 58 to 76 and bands from 225 to 242. Resultantly, 198 bands were established to be useful for further analysis.

Bands 77 and 78 were removed having low Signal to noise value (Datt B, 2003). Water absorption bands 120-132, 165182, 185-187, 221-224, were removed (Beck, 2003). A total of 155 calibrated bands are available for further processing since bands 1-7, 58-78, 80-82, 120-132,165-182,185-187,221-241 are already removed. Thus quick atmospheric correction was applied on remaining 155 calibrated Hyperion imagery. Since imagery is Hyperion orthoimage so no further processing is required.

\subsection{Principal Component Analysis}

PCA was applied on the Atmospheric corrected data set of 155 bands of Hyperion orthoimage. As shown in Table 1, First 10 PCs contain more than 99 percent of the information in a data set of 155 bands. First (PC) contain 97.84 percent of the information. Second, third and fourth PCs contain 1.8 percent of the information. Thus it lead to the conclusion that the dimensionality of the data is around four.

\begin{tabular}{|l|l|l|l|}
\hline PC & Eigenvalue & $\begin{array}{l}\text { Percentage } \\
\text { Variability }\end{array}$ & $\begin{array}{l}\text { Cumulative } \\
\text { Percentage }\end{array}$ \\
\hline 1 & 151.6592 & 97.84 & 97.84 \\
\hline 2 & 1.7765 & 1.15 & 98.99 \\
\hline 3 & 0.6685 & 0.43 & 99.42 \\
\hline 4 & 0.1931 & 0.13 & 99.55 \\
\hline 5 & 0.1520 & 0.09 & 99.64 \\
\hline 6 & 0.0645 & 0.05 & 99.69 \\
\hline 7 & 0.0569 & 0.03 & 99.72 \\
\hline 8 & 0.0468 & 0.03 & 99.75 \\
\hline 9 & 0.0377 & 0.03 & 99.78 \\
\hline 10 & 0.0363 & 0.02 & 99.80 \\
\hline
\end{tabular}

Table 1. Percentage Variability, Cumulative Percentage of first 10 Principal Component Analysis (PCA) of Hyperion orthoimage

The PC1 band contains the largest percentage of data variance and is highly uncorrelated. PC2 band contain the second largest and PC3 contain the third largest data variance and is also uncorrelated. PC4 to PC10 bands appear noisy as they contain very little variance. PC1, PC2 and PC 3 can be used to produce more colourful colour composite images than spectral colour composite images because the data of PCs bands are highly uncorrelated.

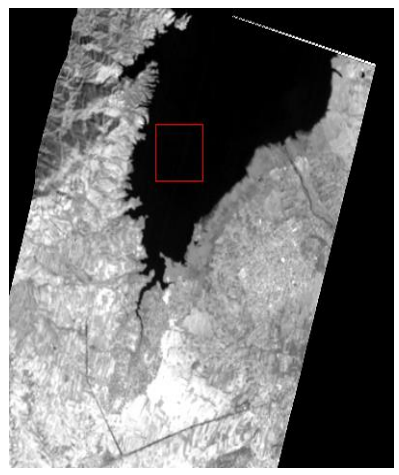

PC1 


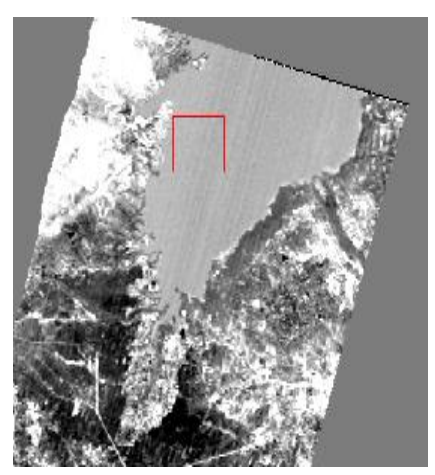

PC2

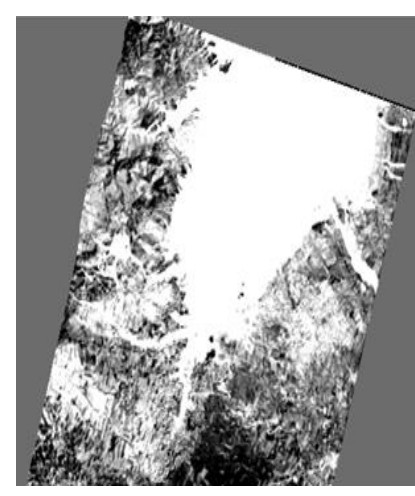

PC3

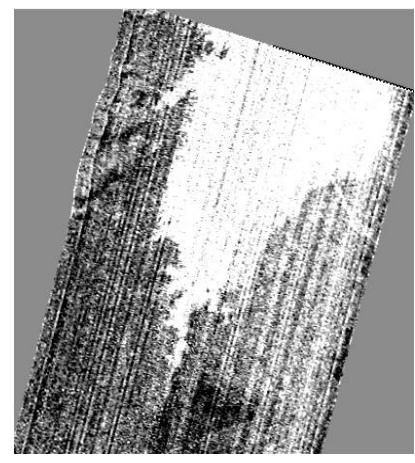

PC4

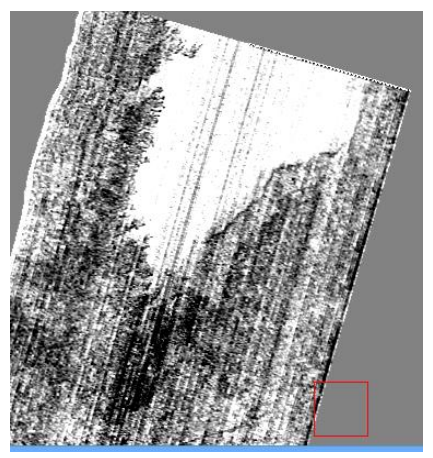

PC5

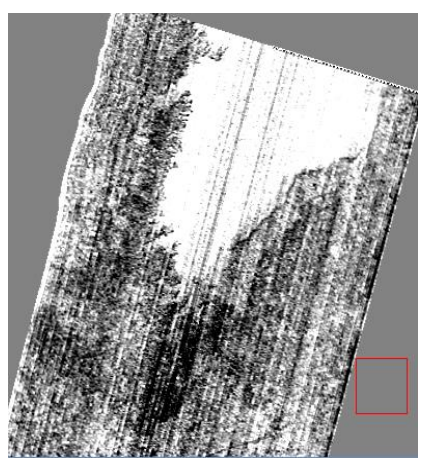

PC6

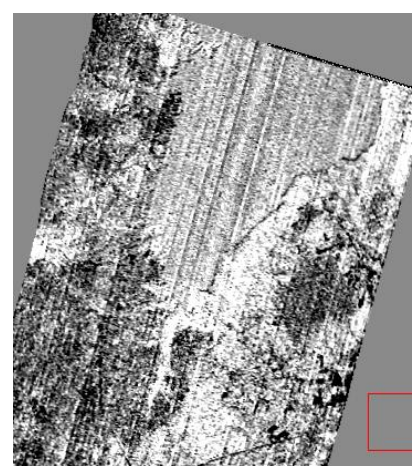

PC7

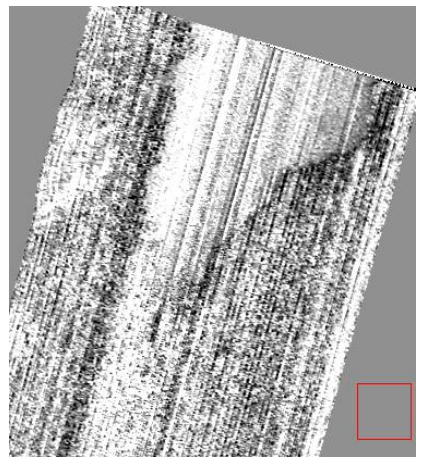

PC8

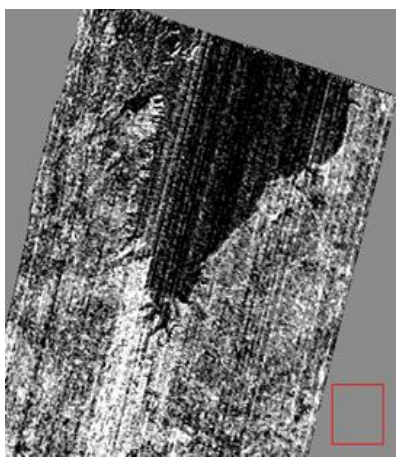

PC9 


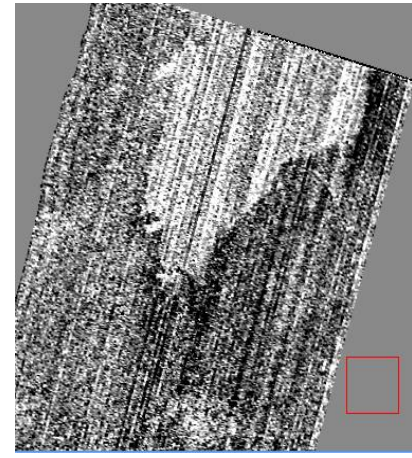

PC10

Figure1. Principal Component (PC) image display (a) PC1 (b) PC2 (c) PC3 (d) PC4 (e) PC5 (f) PC6 (g) PC7 (h) PC8 (i) PC9 (j) PC10

\subsection{NDVI (Normalized Difference Vegetation Index) and Vegetation Delineation}

The surface was covered with many different features which include rocks, vegetation cover, water body and roads. Large area was covered with vegetation class. It was necessary to mask out the vegetation areas. For this purpose NDVI was calculated and vegetation was delineated. Generalized formula for NDVI is as follows:

$$
\text { NDVI }=\underline{\text { NIR-Red }}
$$

For calculating NDVI for Hyperion this formula was transformed as follows:

$$
\left(\lambda_{925.404}-\lambda_{650.6727}\right) /\left(\lambda_{925.404}+\lambda_{650.6727}\right)
$$

Vegetation was classified into three broad categories i.e sparse, moderate and dense. The area under study is covered and divided with no vegetation, sparse, moderate and dense vegetation as shown in the figure 2 . Colour code of the study area of classes versus NDVI values is shown in figure 2. Google earth imagery having high resolution was used to verify the vegetation classes as shown in the figure 3 .

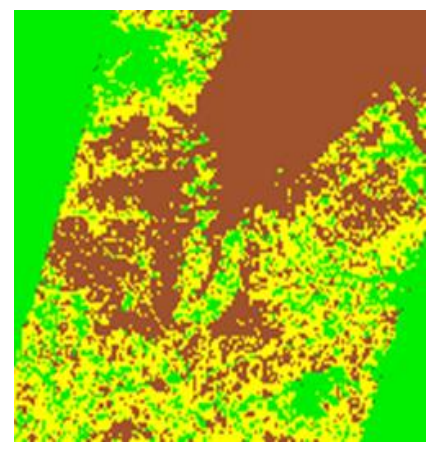

Figure 2. NDVI Vegetation Delineation

\begin{tabular}{|l|l|l|}
\hline Classes & NDVI & Colour Code \\
\hline No Vegetation & -1 & \\
\hline Sparse Vegetation & 0.12 & \\
\hline Moderate Vegetation & 0.24 & \\
\hline Dense Vegetation & 0.50 & \\
\hline
\end{tabular}

Figure 3. Classes versus NDVI values for the study area

\subsection{Spectral Profile of Water and Buildup area}

Water and build-up were also identified using the spectral characteristics of the features. Figure 4 and 5 shows spectral profile of water with radiance and reflectance respectively. Figure 6 and 7 shows the spectral profile of build-up area with radiance and reflectance respectively.

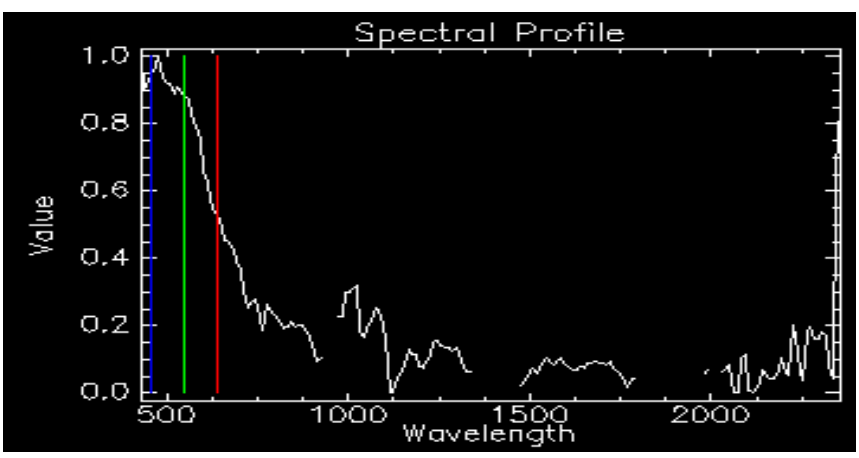

Figure 4. Spectral Profile of Water with radiance

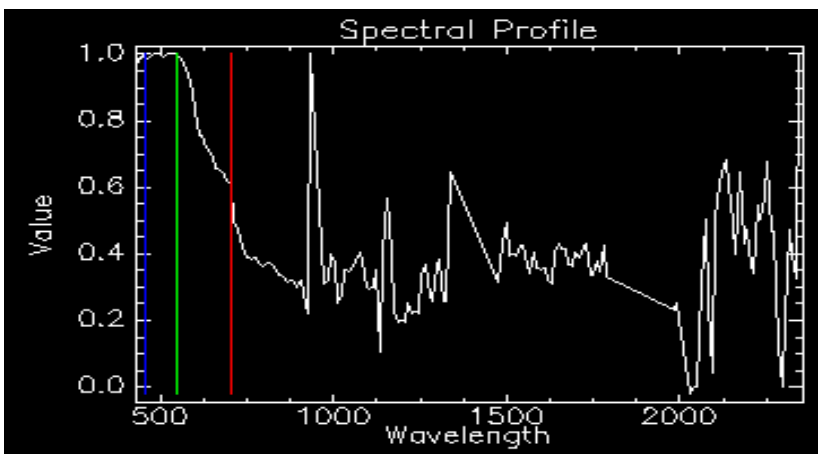

Figure 5. Spectral Profile of Water With Reflectance 


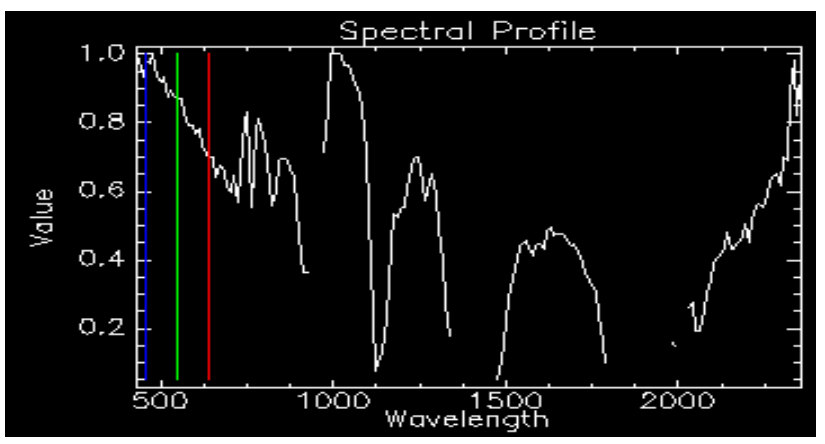

Figure 6. Spectral Profile of Build-up area with radiance

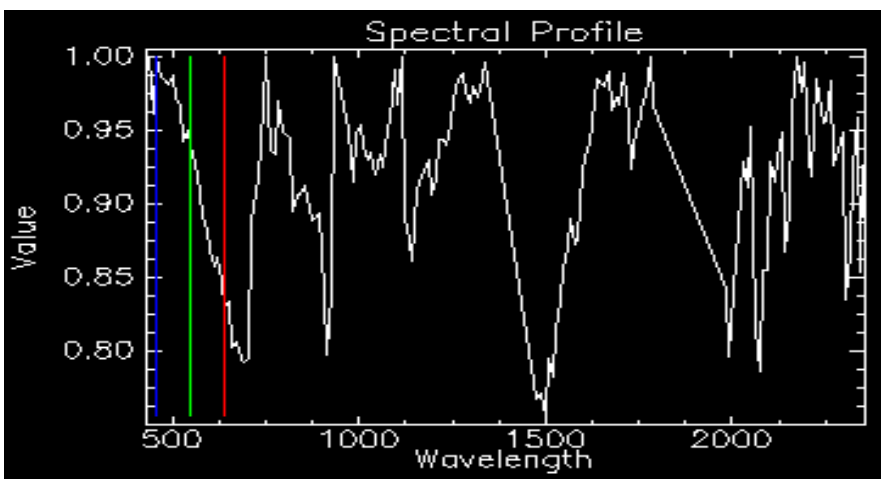

Figure 7. Spectral Profile of Builup area with reflectance

\subsection{Hyperion Classification}

A pixel based supervised classification using spectral angle mapper was carried out on an Hyperion orthoimage. Firstly classes i.e water, build-up, and soil were formulated. Secondly training samples of each of the above mentioned class were collected from the Hyperion orthoimage. Selection of the training samples was supported by the familiarity with the study area and guided by photo interpretation of the aerial imagery. The training samples were taken where land cover change is prominent. Thirdly, the spectral angle mapper classifier was developed and implemented in ENVI using the training samples collected in the preceding steps.
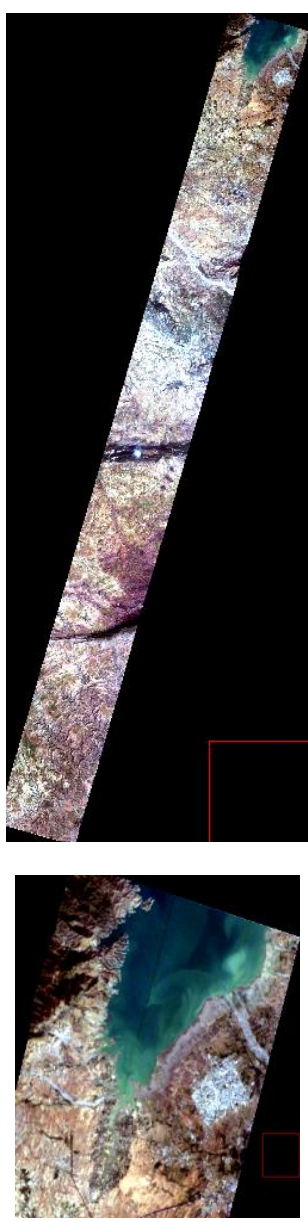

Figure 8. The Acquired Hyperion Orthoimage (top image) and Subset of Acquired Hyperion Orthoimage (bottom image) covering the studied area

\subsection{Classification Accuracy Assessment}

Classification accuracy assessment was developed and implemented in ENVI based on the confusion matrix analysis of the maps produced from the implementation of the spectral angle mapper classification technique on the Hyperion orthoimage. Thus overall accuracy and Kappa coefficient were calculated.

Overall Accuracy $=(3186 / 3676) 86.6703 \%$

Kappa Coefficient $=0.7998$

Ground Truth (Pixels)

\begin{tabular}{|l|l|l|l|l|}
\hline Class & Water & $\begin{array}{l}\text { Buildup } \\
\text { Area }\end{array}$ & Soil & Total \\
\hline Unclassified & 154 & 1 & 3 & 158 \\
\hline Water & 1319 & 0 & 0 & 1319 \\
\hline Buildup Area & 0 & 645 & 260 & 905 \\
\hline Soil & 0 & 72 & 1222 & 1294 \\
\hline Total & 1473 & 718 & 1485 & 3676 \\
\hline
\end{tabular}


Ground Truth (Percent)

\begin{tabular}{|l|l|l|l|l|}
\hline Class & Water & $\begin{array}{l}\text { Buildup } \\
\text { Area }\end{array}$ & Soil & Total \\
\hline Unclassified & 10.45 & 0.14 & 0.20 & 4.30 \\
\hline Water & 89.55 & 0.00 & 0.00 & 35.88 \\
\hline Buildup Area & 0.00 & 89.83 & 17.51 & 24.62 \\
\hline Soil & 0.00 & 10.03 & 82.29 & 35.20 \\
\hline Total & 100.00 & 100.00 & 100.00 & 100.00 \\
\hline
\end{tabular}

\begin{tabular}{|l|l|l|l|l|}
\hline Class & $\begin{array}{l}\text { Commission } \\
\text { (Percent) }\end{array}$ & $\begin{array}{l}\text { Omission } \\
\text { (Percent) }\end{array}$ & $\begin{array}{l}\text { Omission } \\
\text { (Pixels) }\end{array}$ & $\begin{array}{l}\text { Omission } \\
\text { (Pixels) }\end{array}$ \\
\hline Water & 0.00 & 19.45 & $0 / 1319$ & $154 / 1473$ \\
\hline $\begin{array}{l}\text { Buildup } \\
\text { Area }\end{array}$ & 28.73 & 10.17 & $60 / 905$ & $73 / 718$ \\
\hline Soil & 5.56 & 17.71 & $72 / 1294$ & $263 / 1485$ \\
\hline
\end{tabular}

\begin{tabular}{|l|l|l|l|l|}
\hline Class & $\begin{array}{l}\text { Prod. } \\
\text { Acc. } \\
\text { (Percent) }\end{array}$ & $\begin{array}{l}\text { User Acc. } \\
\text { (Percent) }\end{array}$ & $\begin{array}{l}\text { Prod. Acc. } \\
\text { (Pixels) }\end{array}$ & $\begin{array}{l}\text { User Acc. } \\
\text { (Pixels) }\end{array}$ \\
\hline Water & 89.55 & 100.00 & $1319 / 1473$ & $1319 / 1319$ \\
\hline $\begin{array}{l}\text { Buildup } \\
\text { Area }\end{array}$ & 89.83 & 71.27 & $645 / 718$ & $645 / 905$ \\
\hline Soil & 82.29 & 94.44 & $1222 / 1485$ & $1222 / 1294$ \\
\hline
\end{tabular}

\section{CONCLUSION}

Hyperion sensor is today the only "real" space borne hyperspectral sensor in orbit, acquiring spectral information of Earth's surface objects in 242 spectral bands and at spatial resolution of $30 \mathrm{~m}$. Out of 242 spectral bands, 155 calibrated bands are used for further processing. QUAC, quick atmospheric correction has been applied on 155 calibrated bands which have lowered the reflectance of the image in the blue and red region whereas it increases the value of reflectance in the NIR and SWIR region as compared to the apparent reflectance. Principal component analysis is applied to reduce the dimensionality and use the data as conventional bands. From the PCA, it is evident that first 10 PCs contributed more than 99 percent of the information. In this data set of 155 bands, $97.84 \%$ data variability was explained by the first (PC). Another 3 PCs contributed $1.8 \%$ variability. Thus the dimensionality of the data is around four. NDVI and vegetation delineation is used to for vegetation classes feature extraction. Spectral profiles are used for feature extraction of water and build-up areas of the study area. Spectral angle mapper classification, uses an n-D angle to match pixels to reference spectra is a good approach for feature extraction. Accuracy assessment of the derived classification showed the overall efficiency of supervised machine learning classifier spectral angle mapper resulted in 86.6703 and Kappa co-efficient of 0.7998 on hyperspectral image.

\section{REFERENCES}

Agrawal, Gaurav, Bhopal, MANIT, and Sarup, Jyoti, 2011. Comparisons of QUAC and FLAASH Atmospheric Correction Modules on EO-1 Hyperion Data of Sanchi. International Journal of Advanced Engineering Sciences and Technologies, 4(1), pp. 178-186.

Barry, P, 2001. EO-1/Hyperion science data user's guide, Level 1_B. TRW Space, Defense and Information Systems, Redondo Beach, CA, Rep.

Beck, R, 2003. EO-1 User Guide-Version 2.3. Satellite Systems Branch, USGS Earth Resources Observation Systems Data Center (EDC).

Canty, M. J. (in press). Boosting a fast neural network for supervised land cover classification. Computers and Geosciences, 10.1016/j.cageo.2008.07.004.

Chintan, A. S., Arora, M. K., and Pramod, K. V, 2004. Unsupervised classification of hyperspectral data: An ICA mixture model based approach. International Journal of Remote Sensing, 25, pp. 481-487.

Campbell, J. B, 1996. Introduction to remote sensing (2nd ed.). London: Taylor and Francis.

Datt B, McVicar TR, Van Niel TG, Jupp DLB and Pearlman JS, 2003. Preprocessing EO-1 Hyperion hyperspectral Data Support the Application of agricultural Indexes. IEEE Trans Geosci Rem Sens 41, pp. 1246-1259.

Du, P., Tan, K., and Xing, X., 2010. Wavelet SVM in reproducing kernel Hilbert space for hyperspectral remote sensing image classification. Optics Communications, 283, pp. 4978-4984.

Dixon, B., and Candade, N., 2008. Multispectral land use classification using neural networks and support vector machines: One or the other, or both? International Journal of Remote Sensing, 29(4), pp. 1185-1206.

ENVI user guide, 2005.

Green RO, Pavri BE and Chrien TG, 2003. On orbit radiometric and spectral calibration characteristics of EO-1 Hyperion derived with an underflight of AVIRIS and in situ measurements at Salar de Arizaro, Argentina. Rem Sens Envir 41, pp. 1194-1203.

Hong SY, Sudduth KA, Kitchen NR, Drummond ST, Palm HL and Wiebold WJ (2002) Estimating within field variations in soil properties from airborne hyper- spectral images. ISPRS Commission I/ FIOEOS 2002.

Huete AR, Miura T and Gao X, 2003. Land cover conversion and degradation analysis through coupled soil-plan biophysical parameters derived from hyperspectral EO-1 Hyperion. IEEE Trans Geosci Rem Sens 41, pp. 1268-1276. 
Kruse, F. A., 1996. Identification and mapping of minerals in drill core using hyperspectral image analysis of infrared reflectance spectra.

Kruse, F. A., Boardman, J. W., and Huntington, J. F., 2003. Comparison of airborne hyperspectral data and EO-1 Hyperion for mineral mapping. IEEE Transactions on Geoscience and Remote Sensing, 41(6), pp. 1388-1400.

Kruse, FA, Boardman, JW, and Huntington, JF., 2002. Comparison of EO-1 Hyperion and airborne hyperspectral remote sensing data for geologic applications. Paper presented at the Aerospace Conference Proceedings, 2002. IEEE.

Kavzoglu, T., and Colkesen, I., 2009. A kernel functions analysis for support vector machines for land cover classification. International Journal of Applied Earth Observation and Geoinformation, 11, pp. 352-359.

Plaza, J., Plaza, A., Perez, R., and Martinez, P., 2005. Automated generation of semi labeled training samples for nonlinear neural network-based abundance estimation in hyperspectral data. IGARSS 2005, Seoul (S. Korea), pp. 12611264.

Nemmour, H., and Chibani, Y., 2006. Multiple support vector machines for land cover change detection: An application for mapping urban extension. ISPRS Journal of Photogrammetry and Remote Sensing, 61, pp. 125-133.

Plaza, J., Plaza, A., Perez, R., and Martinez, P., 2009. On the use of small training sets for neural network-based characterisation of mixed pixels in remotely sensed hyperspectral images. Pattern Recognition, 42, pp. 3032-3045.

Pengra, Bruce W, Johnston, Carol A, and Loveland, Thomas R., 2007. Mappingan invasive plant, Phragmites australis, in coastal wet lands using the EO-1 Hyperion hyperspectral sensor. Remote Sensing of Environment, 108(1), pp. 74-81.

Pengra, Bruce W, Johnston, Carol A, and Loveland, Thomas R., 2007. Mappingan invasive plant, Phragmites australis, in coastal wet lands using the EO-1 Hyperion hyperspectral sensor. Remote Sensing of Environment, 108(1), pp. 74-81.

Pignatti, S., Cavalli, R. M., Cuomo, V., Fusilli, V., Pascucci, S., Poscolieri, M., et al., 2009. Evaluating Hyperion capability for land cover mapping in a fragmentedecosystem: Pollino National Park, Italy. Remote Sensing of Environment, 113, pp. 622-634.

Small, C., 2001. Estimation of urban vegetation abundance by spectral mixture analysis. International Journal of Remote Sensing, 22, pp. 1305-1334.

Thenkabail PS, Enclona EA, Ashton MS and Meer B Van Der, 2004a. Accuracy assessments of hyperspectral waveband performance for vegetation analysis applications. Rem Sens Envir 91(3-4), pp. 354-376.

Thenkabail PS, Enclona EA, Ashton MS, Legg C and Dieu MJD (2004b) Hyperion, IKONOS, ALI. And ETM+sensors in the study of African rainforests. Rem SensEnvir 90, pp. 23-43.

Wang, J., Chen, Y., He, T., Lv, C., and Liu, A., 2010. Application of geographic image cognition approach in land type classification using Hyperion image: A case study in
China. International Journal of Applied Earth Observation and Geoinformaiton, 12S, pp. S212-S222.

Walsh, S. J., McCleary, A. L., Mena, C. F., Shao, Y., Tuttle, J. P., González, A., et al.(2008). Quick Bird and Hyperion data analysis of an invasive plant species in the Galapagos Islands of Ecuador: Implications for control and land use management. Remote Sensing of Environment, 112, pp. 1927-1941. 